\title{
In vitro anti-neuroblastoma activity of saquinavir and its association with imatinib
}

\author{
FABIO TIMEUS ${ }^{1}$, NICOLETTA CRESCENZIO ${ }^{2}$, ALESSANDRA DORIA ${ }^{2}$, LUISELDA FOGLIA ${ }^{2}$, \\ SARA PAGLIANO $^{2}$, EMANUELA RICOTTI ${ }^{2}$, FRANCA FAGIOLI $^{1}$, PIER ANGELO TOVO $^{2}$ \\ and LUCA CORDERO DI MONTEZEMOLO ${ }^{2}$
}

\author{
${ }^{1}$ Paediatric Haematology-Oncology, Regina Margherita Children's Hospital; ${ }^{2}$ Department of Paediatrics, University \\ of Turin, Regina Margherita Children's Hospital, Piazza Polonia 94, I-10126 Turin, Italy
}

Received September 28, 2011; Accepted October 27, 2011

DOI: $10.3892 /$ or.2011.1582

\begin{abstract}
Neuroblastoma (NB) has a poor prognosis when in advanced stages, highlighting the need for new therapeutic options. The human immunodeficiency virus (HIV) protease inhibitor saquinavir is active in vitro against chronic myeloid leukaemia cells, in synergy with the tyrosine kinase inhibitor imatinib. Here, we evaluated the effects of saquinavir, alone or in association with imatinib, on cell proliferation (count of viable cells after trypan blue exclusion), apoptosis (Annexin V binding) and invasion (through a transwell membrane coated with Matrigel) in SJ-N-KP, IMR5, AF-8, SK-N-SH and SK-N-BE NB lines, all expressing c-kit and PDGF-R (determined by flow cytometry). Saquinavir showed a dose-dependent anti-proliferative and anti-invasive activity on NB lines, increased by the association with imatinib when the two drugs were utilized at clinically attainable concentrations. The same low saquinavir concentrations inhibited in $\mathrm{NB}$ cells the nuclear activation of NF- $\mathrm{KB}$ (Western immunoblotting for nuclear $\mathrm{NF}-\kappa \mathrm{B}$ p50 and p65). Saquinavir at high concentrations also exerted a pro-apoptotic activity on NB lines, significantly increased by the association with imatinib. In conclusion, saquinavir and imatinib are both drugs utilized for long-term therapies, with good oral bioavailability and a well-known toxicity profile. The anti-NB activity of saquinavir and of its association with imatinib suggests a potential usefulness in the treatment of NB, particularly for remission maintenance.
\end{abstract}

Correspondence to: Dr Fabio Timeus, Paediatric HaematologyOncology, Regina Margherita Children's Hospital, Piazza Polonia 94, I-10126 Turin, Italy

E-mail: fabio.timeus@unito.it

Abbreviations: CML, chronic myeloid leukaemia; NB, neuroblastoma

Key words: saquinavir, imatinib, HIV protease inhibitors, neuroblastoma cell lines

\section{Introduction}

Human immunodeficiency virus (HIV) protease inhibitors (PIs) are widely utilized antiretroviral drugs (1) which also show anti-cancer activity. Since the initial observation that they promote regression of Kaposi sarcoma by inhibiting angiogenesis (2), their direct antitumour effects have been documented on various tumour cell lines, such as human prostate carcinoma, glioblastoma, leukaemia, non-small cell lung cancer and melanoma (3-6). This antitumour activity has been related to impaired proteasome function, inhibition of cyclin-dependent kinase (CDK) 2 and a decrease in growth factor-induced or endogenous Akt-driven signalling (6-10). In other experimental models, PIs at therapeutic dosages have been shown to affect the proteolytic activity of purified human proteasomes and to prevent NF- $\mathrm{KB}$ activation (11). According to the above reports, we previously demonstrated that the PI saquinavir exerts inhibitory and pro-apoptotic activity on chronic myeloid leukaemia (CML) cells, in synergy with imatinib, with a stronger effect on the imatinib-resistant CML cell lines (12). These saquinavir-mediated effects were associated with a reduced NF- $\kappa \mathrm{B}$ nuclear translocation. Imatinib, also defined as STI571, was initially described to inhibit the in vitro growth of Bcr-Abl-positive CML cells through selective inhibition of the Abl tyrosine kinase, and then proved to exert inhibitory activity on tyrosine kinase receptors such as c-kit and platelet-derived growth factor receptor (PDGF-R) (13).

Neuroblastoma (NB) is the third most common paediatric cancer. It is an embryonic cancer derived from the peripheral sympathetic nervous system with a heterogeneous clinical course ranging from spontaneous regression to very aggressive forms. In advanced disease stages, NB has, in spite of aggressive multimodal therapy (14), a poor prognosis, with a long-term survival of $<40 \%$ in high risk patients, thus highlighting the need for new therapeutic options (15-19). A number of observations indicate that c-kit, PDGFR and their ligands play a substantial role in the survival and proliferation of NB cells (20-24). Imatinib is active against NB cells in vitro and in xenografts (24-27), but it shows little or no activity as a single agent in children with relapsed or refractory NB (28). 
The aim of the present study was to investigate the effects of saquinavir alone or in combination with imatinib in NB cell lines, in order to evaluate a possible additive antitumor activity of the two drugs.

\section{Materials and methods}

Saquinavir and imatinib stock solutions. Saquinavir (Roche, UK) and Imatinib (STI571; Novartis Pharmaceuticals, Basel, Switzerland), were solubilized in $100 \%$ dimethyl sulfoxide (DMSO) at final concentrations of 40 and $1 \mathrm{mM}$, respectively, and used as the stock solution for all experiments.

Cell cultures. The NB cell lines SJ-N-KP, IMR5, AF-8, SK-N$\mathrm{SH}$, SK-N-BE (29-31) were maintained in monolayer cultures in RPMI-1640 medium supplemented with 10 or $1 \%$ fetal calf serum (FCS), $2 \mathrm{mM}$ L-glutamine, $100 \mu \mathrm{g} / \mathrm{ml}$ streptomycin and $100 \mathrm{IU} / \mathrm{ml}$ penicillin at $37^{\circ} \mathrm{C}$ in a $5 \% \mathrm{CO}_{2}$ humidified atmosphere.

Flow cytometry for PDGF-R $\beta$. SJ-N-KP, IMR5, AF-8, SK-N-SH, SK-N-BE cells $\left(5 \times 10^{5}\right)$ were incubated with an anti-PDGF-R $\beta$ chain monoclonal antibody (R\&D Systems, Minneapolis MN, USA) for $20 \mathrm{~min}$ at $4^{\circ} \mathrm{C}$. After washing, the cells were incubated with $\mathrm{PE}$-conjugated goat anti-mouse secondary antibody (BD Pharmingen, San Diego, CA, USA) for $30 \mathrm{~min}$ and then analyzed by a BD FACSCanto (BD Pharmingen). The osteosarcoma cell line SJSA-1 (obtained from the American Type Culture Collection) was utilized as a positive control.

Cell proliferation assays. The exponentially growing SJ-NKP, IMR5, AF-8, SK-N-SH, SK-N-BE cell lines were cultured in the presence or absence of saquinavir from 0.1 up to $40 \mu \mathrm{M}$, imatinib from 0.001 to $50 \mu \mathrm{M}$ or the association of saquinavir $5 \mu \mathrm{M}$ with increasing imatinib concentrations for 24,48 or $72 \mathrm{~h}$. Following exposure to the drugs or DMSO (control), the cells were trypsinized, harvested and stained with trypan blue for their viability evaluation. Cellular proliferation was determined by quantifying viable cells manually using a haemocytometer. Inhibiting concentrations of $50 \%\left(\mathrm{IC}_{50}\right)$ were calculated by nonlinear regression analysis using the SPSS 11.5 software package (SPSS, Inc., Chicago, IL, USA). Experiments were performed in triplicate.

Because there is a reported interference of imatinib with the most commonly utilized MTT test which can lead to erroneous results (32), this technique was avoided.

Apoptosis assays. Following 24, 48 and $72 \mathrm{~h}$ exposure of SJ-N-KP, IMR5, AF-8, SK-N-SH, SK-N-BE cells to various concentrations (Fig. 3) of saquinavir, imatinib, imatinib plus saquinavir $5 \mu \mathrm{M}$ or DMSO (control) in the presence of 1 or $10 \%$ FCS, the cells were trypsinized and harvested. Apoptosis was evaluated by two colour-flow cytometry, using Annexin V-FITC conjugates (apoptosis detection kit, R\&D Systems), according to the manufacturer's instructions, with an EPICS XL2 Coulter flow cytometer (Beckman Coulter, Inc., Brea, CA, USA). This method evaluates cells in early (Annexin $\mathrm{V}^{+}$/propidium iodide ${ }^{-}$) and late apoptosis (Annexin $\mathrm{V}^{+}$/propidium iodide ${ }^{+}$). Experiments were performed in triplicate.
Invasion assays. Cell migration was evaluated in SJ-N-KP, IMR5, AF-8, SK-N-SH, SK-N-BE cell lines using 24-well transwell plates $(6.5-\mathrm{mm}$ diameter) with an $8-\mu \mathrm{m}$ pore size polycarbonate membrane (Corning Costar, MA, USA) coated with Matrigel (BD Pharmingen) $1.25 \mu \mathrm{g} / \mu \mathrm{l}$. The lower compartment was filled with $600 \mu \mathrm{l}$ of IMDM containing $10 \%$ FCS as a chemoattractant. NB cells $\left(2 \times 10^{4}\right)$ resuspended in $100 \mu \mathrm{l}$ of IMDM containing $1 \% \mathrm{FCS}$ in the presence of saquinavir 5, $10,20 \mu \mathrm{M}$, imatinib $0.01 \mu \mathrm{M}$ alone or imatinib $0.01 \mu \mathrm{M}$ plus saquinavir $5 \mu \mathrm{M}$ were added into the upper well and incubated at $37^{\circ} \mathrm{C}$. After $24 \mathrm{~h}$ incubation, the cells on the upper side of the membrane were removed with a cotton swab and the cells on the lower side of the membrane were fixed and stained with crystal violet. The cells on the entire lower surface of the membrane, visualized with an inverted microscope, were counted in 5 fields under a x400 magnification. The experiments were carried out in triplicate.

Preparation of nuclear extracts. NB cells treated with or without $5 \mu \mathrm{M}$ saquinavir for $16 \mathrm{~h}$ were stimulated with PMA (phorbol 11-myristate-12-acetate, Sigma-Aldrich, St. Louis, MO, USA) $10 \mathrm{ng} / \mathrm{ml}$ and calcium ionophore (Sigma-Aldrich) $500 \mathrm{ng} / \mathrm{ml}$ for $15 \mathrm{~min}$. After incubation, cells were washed twice with ice-cold phosphate-buffered saline. Pellets were resuspended in buffer A (HEPES 10 mM pH 7.9, KCl 10 mM, PMSF 1 mM, DTT 1 mM) and cells were homogenized using insulin syringes. After $45 \mathrm{~min}$ incubation at $4^{\circ} \mathrm{C}$ samples were centrifuged at $12,000 \mathrm{rpm}$ for $10 \mathrm{~min}$. Nuclei were extracted in buffer C (HEPES $20 \mathrm{mM} \mathrm{pH}$ 7.8, $\mathrm{MgCl}_{2} 1.5 \mathrm{mM}, \mathrm{NaCl} 420 \mathrm{mM}$, EDTA $0.2 \mathrm{mM}$, PMSF $1 \mathrm{mM}$, DTT $1 \mathrm{mM}$, and $25 \%$ glycerol) for $30 \mathrm{~min}$ on ice, then cleared by centrifugation $\left(12,000 \mathrm{rpm}\right.$ for $30 \mathrm{~min}$ at $\left.4^{\circ} \mathrm{C}\right)$. Protein concentration was determined by the Micro BCA protein assay reagent kit (Pierce Chemical, Rockford, IL, USA), following the manufacturer's instructions.

Western blot analysis. Samples containing equal amounts of protein $(20 \mu \mathrm{g})$ were resolved on $11 \%$ SDS-polyacrylamide gels (SDS-PAGE). Resolved proteins were electrotransferred onto PVDF membrane, blocked overnight with $5 \% \mathrm{w} / \mathrm{v}$ BSA (Sigma-Aldrich) in TBS (Tris $20 \mathrm{mM} \mathrm{pH} \mathrm{7.6,} \mathrm{NaCl} 140 \mathrm{mM}$ ) containing $0.1 \%$ Tween-20 (blocking solution) and probed with primary antibodies anti-p65 and anti-p50 (Santa Cruz Biotechnology, Inc., Heidelberg, Germany). Immunoreactive bands were detected by ECL. Blots were stripped (glycine $200 \mathrm{mM}$, SDS $0.1 \%$, Tween $1 \% \mathrm{pH} 2.2$ ) and reprobed with anti SP-1 (Santa Cruz Biotechnology) and detected by ECL. Relative band intensities were quantified using Quantity one image analysis software (Bio-Rad, CA, USA).

Statistical analysis. Drug concentrations causing a $50 \%$ inhibition of cellular growth $\left(\mathrm{IC}_{50}\right)$ were calculated by nonlinear regression analysis using the SPSS 11.5 software package (SPSS, Inc.). Student's t-tests were used to analyse the drug effects on cell proliferation, apoptosis and migration. P-values $<0.05$ were considered statistically significant.

\section{Results}

$N B$ cell lines express PDGF-R $\beta$. Flow cytometry demonstrated in SJ-N-KP, IMR5, AF-8, SK-N-SH and SK-N-BE cell lines the 

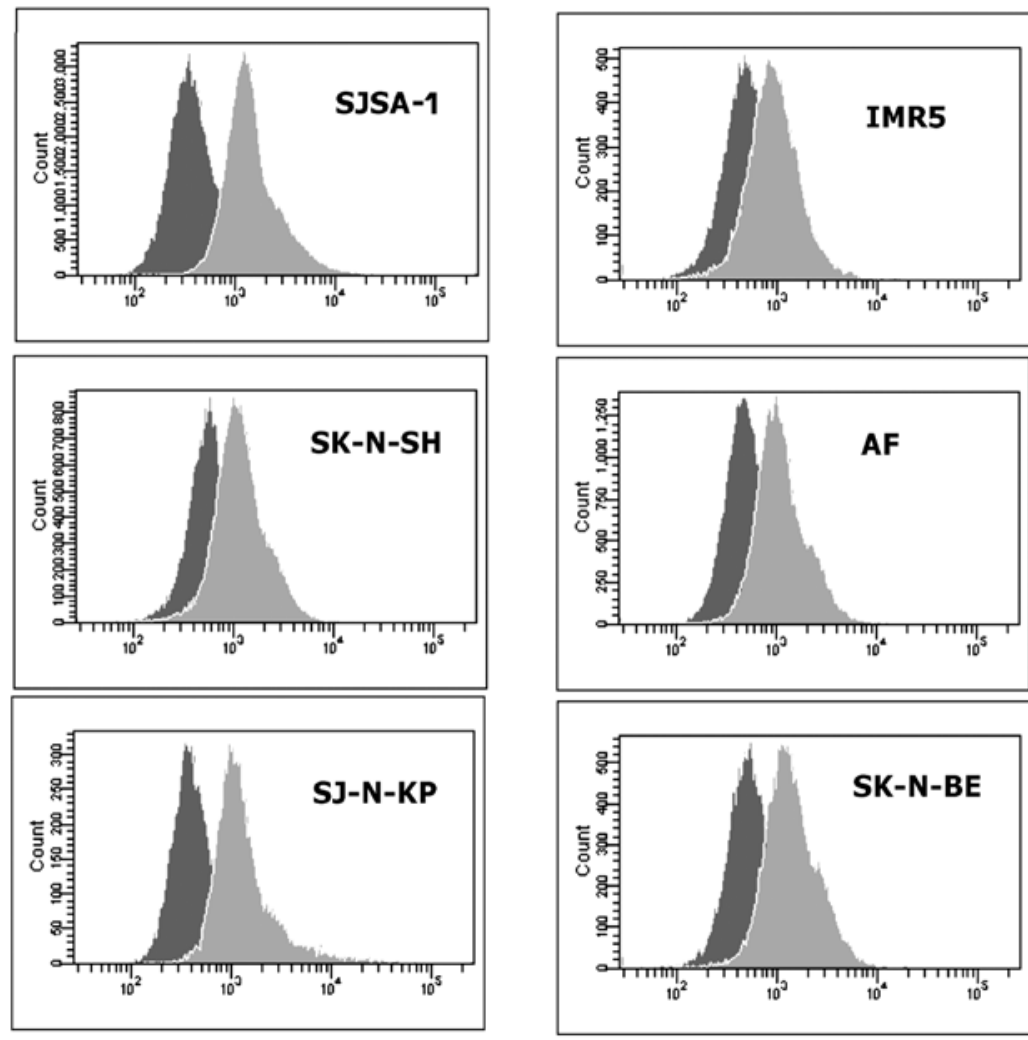

Figure 1. SJ-N-KP, IMR5, AF-8, SK-N-SH and SK-N-BE neuroblastoma cell lines express membrane PDGF-R $\beta$. Flow cytometric analysis was performed by an anti-PDGF-R $\beta$ chain monoclonal antibody on cells cultured in RPMI-1640 plus 10\% FCS. The osteosarcoma cell line SJSA-1 was utilised as a positive control.

Table I. $\mathrm{IC}_{50}$ of saquinavir and imatinib in NB cell lines.

\begin{tabular}{|c|c|c|c|c|c|c|c|c|c|}
\hline & \multicolumn{3}{|c|}{$24 \mathrm{~h}$} & \multicolumn{3}{|c|}{$48 \mathrm{~h}$} & \multicolumn{3}{|c|}{$72 \mathrm{~h}$} \\
\hline & Saq & $\operatorname{Im}$ & $\mathrm{Saq}+\mathrm{Im}$ & Saq & $\mathrm{Im}$ & $\mathrm{Saq}+\mathrm{Im}$ & Saq & $\mathrm{Im}$ & $\mathrm{Saq}+\mathrm{Im}$ \\
\hline SJ-N-KP & 6.96 & 2.01 & 0.02 & 3.17 & 2.70 & 0.27 & 3.80 & 1.85 & 0.34 \\
\hline IMR5 & 6.91 & 4.01 & 0.07 & 3.96 & 2.14 & 0.26 & 3.62 & 1.36 & 0.29 \\
\hline AF-8 & 6.56 & 4.54 & 0.63 & 3.72 & 1.07 & 0.08 & 4.44 & 0.99 & 0.08 \\
\hline SK-N-SH & 6.54 & 1.79 & 0.10 & 3.33 & 0.63 & 0.02 & 2.49 & 0.76 & 0.02 \\
\hline SK-N-BE & 4.78 & 2.63 & 0.41 & 4.73 & 1.27 & 0.18 & 3.67 & 0.98 & 0.03 \\
\hline
\end{tabular}

$\mathrm{IC}_{50}$ (expressed in $\mu \mathrm{M}$, calculated by non-linear regression analysis) of saquinavir (Saq), imatinib alone (Im) and imatinib in association with saquinavir $5 \mu \mathrm{M}(\mathrm{Im}+\mathrm{Saq})$ in SJ-N-KP, IMR5, AF-8, SK-N-SH and SK-N-BE cell lines.

expression of membrane PDGF-R $\beta$ at comparable levels (Fig. 1). The expression of c-kit in the same lines has been previously described by our group (22). PDGF-R $\beta$ and c-kit expression provide the rationale for the use of imatinib in our study.

Saquinavir alone and in combination with imatinib inhibits $N B$ cell line proliferation. Proliferation assays were carried out on SJ-N-KP, IMR5, AF-8, SK-N-SH and SK-N-BE cell lines exposed for 24,48 or $72 \mathrm{~h}$ to saquinavir or imatinib or the two drugs in combination. As single agent saquinavir demonstrated a concentration-dependent antiproliferative effect. The association of saquinavir $5 \mu \mathrm{M}$ with various concentrations of imatinib caused a significant increase of the imatinib antiproliferative activity (considering all cell lines taken together: saquinavir
$5 \mu \mathrm{M}$ plus imatinib from 0.001 to $10 \mu \mathrm{M}$ vs. imatinib alone at the same concentrations; $\mathrm{P}<0.01$ after $24,48,72 \mathrm{~h}$ exposure). Proliferation assay results and saquinavir $\mathrm{IC}_{50}$ values are shown in Fig. 2 and Table I).

Saquinavir alone and in combination with imatinib inhibits $N B$ cell invasion through the matrigel matrix. Cell invasion assays showed a significant inhibitory effect of saquinavir at 5,10 or $20 \mu \mathrm{M}$ on cell invasion in SJ-N-KP, IMR5, AF-8, SK-N-SH and SK-N-BE cell lines ( $\mathrm{P}<0.0001$ vs. control, RPMI-1640 plus DMSO) (Table II). Imatinib alone at $0.01 \mu \mathrm{M}$ also inhibited cell migration. The association of imatinib $0.01 \mu \mathrm{M}$ with saquinavir $5 \mu \mathrm{M}$ significantly increased the antiinvasive activity of the single compounds (saquinavir $5 \mu \mathrm{M}$ 

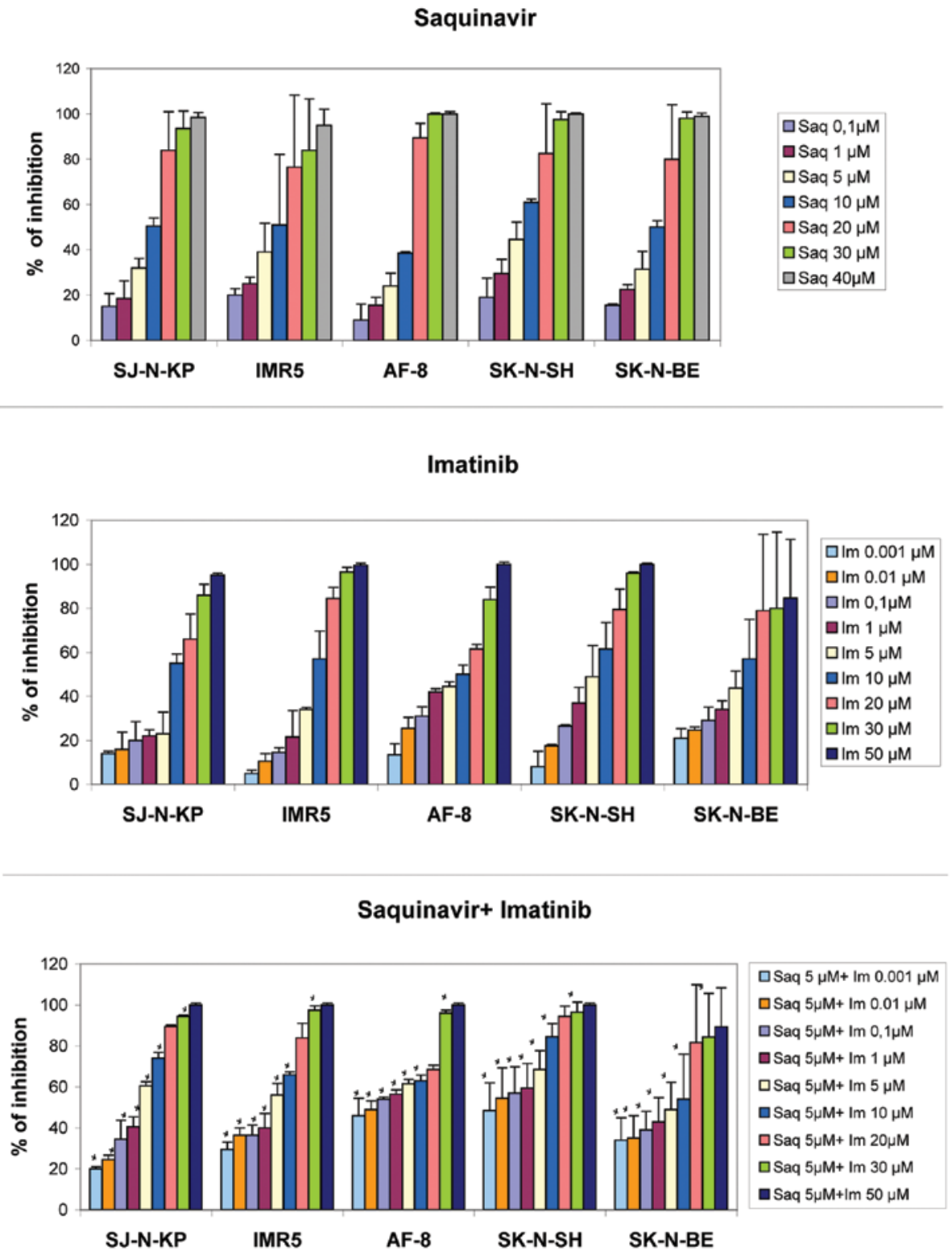

Figure 2. Saquinavir, imatinib and their combination inhibit neuroblastoma SJ-N-KP, IMR5, AF-8, SK-N-SH and SK-N-BE cell line proliferation in a dosedependent manner. The figure shows the percentage of inhibition of cell proliferation compared to DMSO (drug vehicle) after $72 \mathrm{~h}$ exposure to the drugs alone or in combination. Data are the mean \pm SD of three independent experiments and are expressed as $\%$ of inhibition in treated cells. Statistical significance of the combination of saquinavir $5 \mu \mathrm{M}$ with various concentrations of imatinib compared to imatinib alone, ${ }^{*} \mathrm{P}<0.01$.

Table II. Inhibition of NB cell invasion in the presence of saquinavir and imatinib.

\begin{tabular}{lccccc}
\hline & $\begin{array}{c}\text { SJ-N-KP } \\
(\%)\end{array}$ & $\begin{array}{c}\text { IMR5 } \\
(\%)\end{array}$ & $\begin{array}{c}\text { AF-8 } \\
(\%)\end{array}$ & $\begin{array}{c}\text { SK-N-SH } \\
(\%)\end{array}$ & $\begin{array}{c}\text { SK-N-BE } \\
(\%)\end{array}$ \\
\hline $5 \mu \mathrm{M} \mathrm{Saq}$ & $39 \pm 8.5$ & $48 \pm 4.9$ & $35 \pm 12.0$ & $33 \pm 7.1$ & $33 \pm 9.2$ \\
$10 \mu \mathrm{M} \mathrm{Saq}$ & $46 \pm 9.9$ & $59 \pm 6.4$ & $55 \pm 0.2$ & $46 \pm 0.5$ & $55 \pm 11.3$ \\
$20 \mu \mathrm{M} \mathrm{Saq}$ & $67 \pm 4.9$ & $72 \pm 15.5$ & $71 \pm 7.1$ & $69 \pm 12.7$ & $75 \pm 8.5$ \\
$0.01 \mu \mathrm{M} \mathrm{Im}$ & $54 \pm 9.9$ & $52 \pm 8.5$ & $35 \pm 1.0$ & $45 \pm 7.1$ & $31 \pm 16$ \\
$0.01 \mu \mathrm{M} \mathrm{Im}+5 \mu \mathrm{M} \mathrm{Saq}$ & $67 \pm 9.2$ & $66 \pm 11.3$ & $63 \pm 12.0$ & $56 \pm 12.7$ & $65 \pm 3.5$ \\
\hline
\end{tabular}

Evaluation of cell invasion through transwell plates with $8-\mu \mathrm{m}$ pore size polycarbonate membrane in SJ-N-KP, IMR5, AF-8, SK-N-SH, SK-N-BE cell lines. Data are expressed as percentages of inhibition of migration compared to the control after 24 h-exposure to saquinavir alone at various concentrations, imatinib $0.01 \mu \mathrm{M}$ or saquinavir $5 \mu \mathrm{M}$ plus imatinib $0.01 \mu \mathrm{M}$. Values are the mean \pm standard deviation of three independent experiments. The association of imatinib $0.01 \mu \mathrm{M}$ with saquinavir $5 \mu \mathrm{M}$ significantly increased the anti-migratory activity of saquinavir $5 \mu \mathrm{M}$ alone $(\mathrm{P}<0.0001)$. Saq, saquinavir; Im, imatinib. 
24h

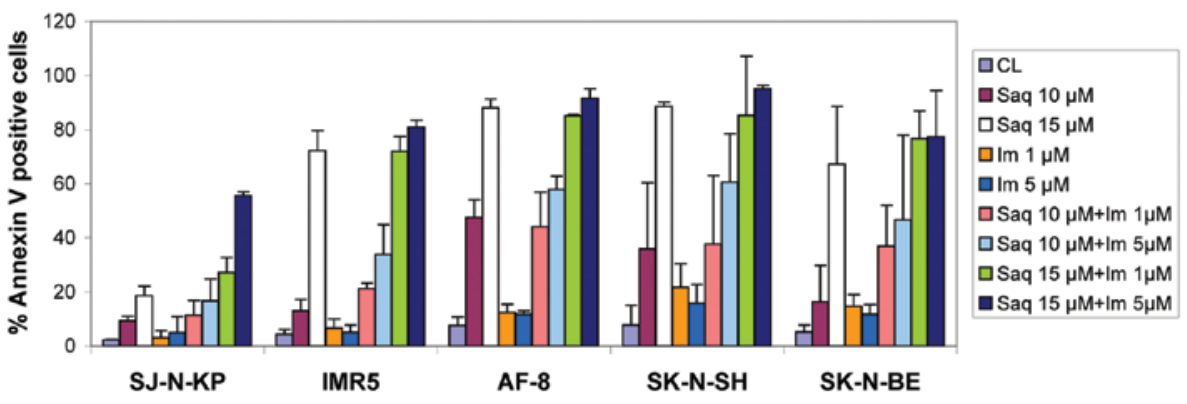

$48 \mathrm{~h}$

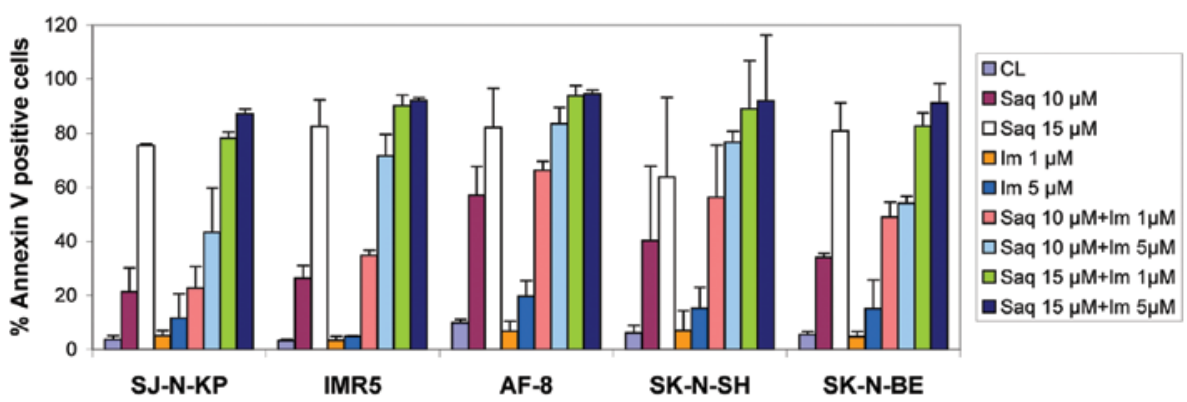

$72 \mathrm{~h}$

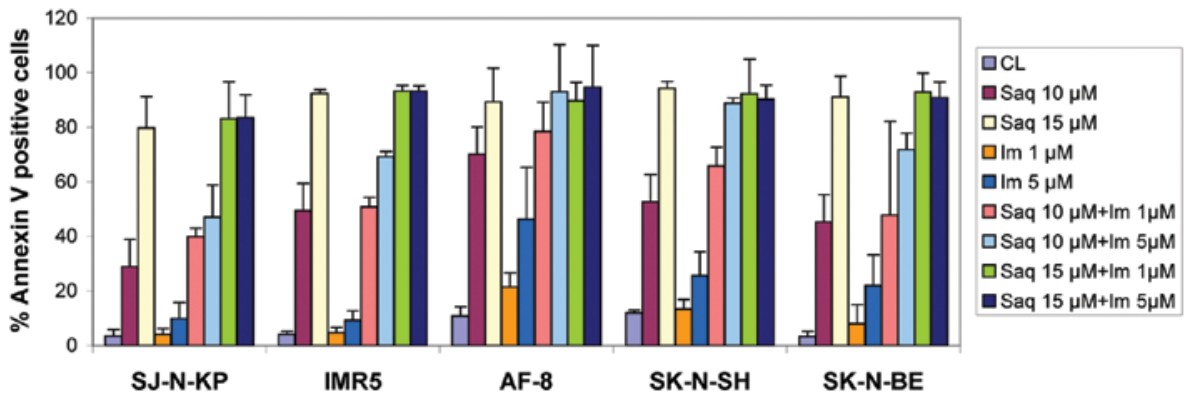

Figure 3. Saquinavir exerts a pro-apoptotic activity on neuroblastoma SJ-N-KP, IMR5, AF-8, SK-N-SH and SK-N-BE cell lines in a dose-dependent manner The figure shows the percentage of apoptotic cells after exposure to saquinavir alone (Saq), imatinib alone (Im) or the combination of various concentrations of saquinavir and imatinib. Cultures were carried out for 24, 48, $72 \mathrm{~h}$ in the presence of $1 \%$ FCS. The association with imatinib significantly increased the pro-apoptotic activity of saquinavir (saquinavir $10 \mu \mathrm{M}$ in combination with imatinib $5 \mu \mathrm{M}$ vs. saquinavir $10 \mu \mathrm{M}$ : $\mathrm{P}<0.05$ after $24 \mathrm{~h}, \mathrm{P}<0.001$ after $48 \mathrm{~h}, \mathrm{P}<0.001$ after $72 \mathrm{~h}$ ). The data express the mean percentage \pm SD of three independent experiments.

plus imatinib $0.01 \mu \mathrm{M}$ vs. saquinavir $5 \mu \mathrm{M}$ alone $\mathrm{P}<0.001$; saquinavir $5 \mu \mathrm{M}$ plus imatinib $0.01 \mu \mathrm{M}$ vs. imatinib $0.01 \mu \mathrm{M}$ alone $\mathrm{P}<0.001)$.

Saquinavir exerts a pro-apoptotic activity on NB cell lines. In cells cultured in the presence of $10 \%$ FCS, a significant saquinavir pro-apoptotic activity was observed only at concentrations of $20 \mu \mathrm{M}$ or higher (data not shown). In SJ-N-KP, IMR5, AF-8, SK-N-SH, SK-N-BE cells cultured in the presence of $1 \%$ FCS, saquinavir exhibited a significant concentration and time-dependent pro-apoptotic activity also at lower concentrations (10 and $15 \mu \mathrm{M} ; \mathrm{P}<0.01)$ (Fig. 3). We did not observe a significant difference in the percentage of apoptotic cells between the control experiments carried-out in the presence of $1 \%$ FCS and the control experiments carriedout in the presence of $10 \%$ FCS (data not shown), ruling out a possible pro-apoptotic effect of low concentrations of FCS. Imatinib at concentrations of 1 and $5 \mu \mathrm{M}$ caused a negligible pro-apoptotic effect on the SJ-N-KP, IMR5, AF-8, SK-N-SH, SK-N-BE cell lines, whereas the association with imatinib significantly increased the pro-apoptotic activity of saquinavir (saquinavir $10 \mu \mathrm{M}$ in combination with imatinib $5 \mu \mathrm{M}$ vs. saquinavir $10 \mu \mathrm{M}: \mathrm{P}<0.05$ after $24 \mathrm{~h} ; \mathrm{P}<0.001$ after $48 \mathrm{~h}$; $\mathrm{P}<0.001$ after $72 \mathrm{~h}$ ).

Saquinavir inhibits nuclear translocation of $N F-\kappa B$ in $N B$ cells. Western blotting experiments demonstrated a significant reduction of nuclear p65 and p50 in PMA-stimulated NB cells after exposure to saquinavir $5 \mu \mathrm{M}$. Fig. 4 shows a representative analysis in the SJ-N-KP cell line.

\section{Discussion}

The direct anti-cancer activity of some HIV PIs has been previously described (2-6). In the present study a significant dosedependent anti-proliferative effect of saquinavir was observed in 

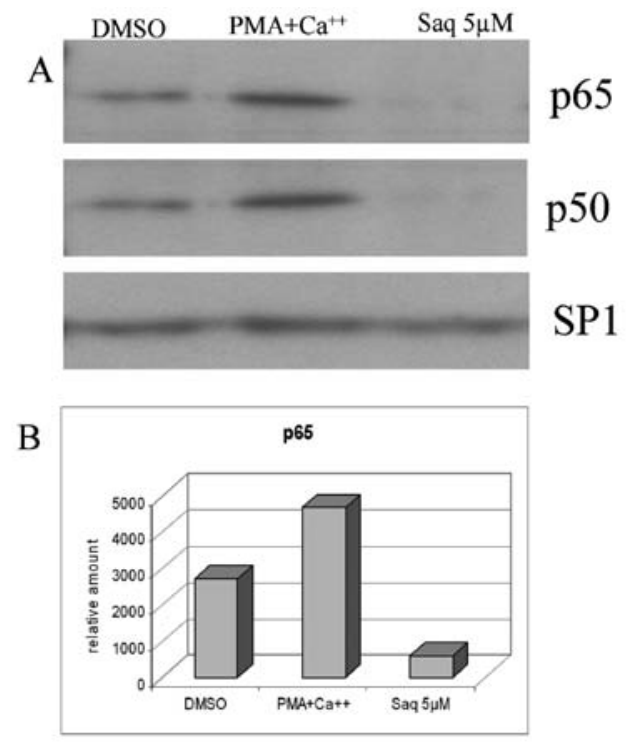

concentrations, suggesting an anti-metastatic effect that might have a significant impact on the outcome of NB patients.

In the presence of $10 \%$ FCS, saquinavir exerted a significant pro-apoptotic activity on NB cell lines at concentrations of $20 \mu \mathrm{M}$ or higher. However, in the cultures carried out in the presence of $1 \%$ FCS, saquinavir exhibited a significant pro-apoptotic activity at lower and clinically attainable concentrations, while low concentrations of FCS had not per se a pro-apoptotic activity as shown in control experiments. This might be explained by an anti-apoptotic activity of high concentrations of serum, as demonstrated in other experimental models (36). Imatinib alone had a negligible pro-apoptotic effect on NB cell lines, whereas the association with imatinib significantly increased the pro-apoptotic activity of saquinavir.

Altogether, our data suggest that, in NB cell lines, the antiproliferative and anti-invasive activity of saquinavir, observed in the presence of $10 \% \mathrm{FCS}$, is prominent compared to its pro-apoptotic activity. Since some NB cell lines in the study were reported to be MYCN-unamplified/low-expressed (37) and some MYCN-amplified/overexpressed (IMR5) $(38,39)$, the biological effects of saquinavir and of its association with imatinib on NB cell lines seem independent from MYCN amplification.

Pajonk et al (6) evidenced that saquinavir inhibits $\mathrm{NF}-\kappa \mathrm{B}$ activation in prostate carcinoma cells. Here we show that low saquinavir concentrations inhibit NF- $\mathrm{B}$ p50 and p65 activation in NB cells. The ubiquitin-proteasome pathway plays a key role in the activation of NF- $\mathrm{KB}$ and in the degradation of its inhibitor Iк-B. HIV PIs at therapeutic concentrations block proteasome activities (11) and thus may impair a large array of biological activities, such as cell-cycle progression, angiogenesis, and activation of transcriptional factors. The inhibitory effects of saquinavir on proteasome functions and $\mathrm{NF}-\kappa \mathrm{B}$ activation may account, at least partially, for its antitumoral properties.

In conclusion, saquinavir is a drug utilized in the long-

$\mathrm{NB}$ cell lines. It is worth noting that the $\mathrm{IC}_{50}$ determined in the present study was about 1 log lower than in the leukaemic K562 line (12).

Imatinib, a selective inhibitor of the tyrosine kinase activity of c-kit and PDGF-R, is active in vitro against NB cell lines (24-27). However, in spite of the pivotal role played by PDGF-R and c-kit in promoting cell proliferation and migration and in inhibiting apoptosis in NB cell lines (20-24), imatinib has shown little or no activity as a single agent in children with relapsed or refractory NB (28). The observation that imatinib is more effective in preventing the cell proliferation of CML lines when in combination with saquinavir (12) prompted us to investigate the effects of the association of saquinavir plus imatinib on the five NB cell lines, all expressing c-kit and PDGF-R. In the present study the association of saquinavir and imatinib showed an additive anti-proliferative activity at clinically attainable concentrations $(33,34)$ of both compounds.

Saquinavir also exerted an anti-invasive activity on NB cells. This is in line with Sgadari et al (2) that PIs block Kaposi sarcoma cell invasion. Vitali et al (35) previously described an anti-migratory activity of imatinib in NB. Here, we demonstrated a significant increase of the anti-invasive activity of imatinib when associated with saquinavir at therapeutic term treatment of HIV seropositive patients, with good oral bioavailability and a well known toxicity profile. Its antiproliferative and anti-invasive effects on NB cell lines at therapeutic concentrations suggest a potential usefulness for the treatment of NB, particularly for remission maintenance. The additive activity of low concentrations of saquinavir and imatinib seems of particular interest. Targeted animal studies are warranted.

\section{Acknowledgements}

This study was partially supported by a grant from the Unione Genitori Italiani contro il tumore dei bambini (UGI). We thank Mr. Andrew Martin Garvey for editorial assistance.

\section{References}

1. Hammer SM, Eron JJ Jr, Reiss P, et al; International AIDS Society-USA: Antiretroviral treatment of adult HIV infection: 2008 recommendations of the International AIDS Society-USA panel. JAMA 300: 555-570, 2008.

2. Sgadari C, Barillari G, Toschi E, et al: HIV protease inhibitors are potent anti-angiogenic molecules and promote regression of Kaposi sarcoma. Nat Med 8: 225-232, 2002. 
3. Gills JJ, Lopiccolo J, Tsurutani J, et al: Nelfinavir, A lead HIV protease inhibitor, is a broad-spectrum, anticancer agent that induces endoplasmic reticulum stress, autophagy, and apoptosis in vitro and in vivo. Clin Cancer Res 13: 5183-5194, 2007.

4. Ikezoe T, Daar ES, Hisatake J, Taguchi H and Koeffler HP: HIV-1 protease inhibitors decrease proliferation and induce differentiation of human myelocytic leukemia cells. Blood 96: 3553-3559, 2000.

5. Ikezoe T, Hisatake Y, Takeuchi T, et al: HIV-1 protease inhibitor, ritonavir: a potent inhibitor of CYP3A4, enhanced the anticancer effects of docetaxel in androgen-independent prostate cancer cells in vitro and in vivo. Cancer Res 64: 7426-7431, 2004.

6. Pajonk F, Himmelsbach J, Riess K, Sommer A and McBride WH: The human immunodeficiency virus (HIV)-1 protease inhibitor saquinavir inhibits proteasome function and causes apoptosis and radiosensitization in non-HIV-associated human cancer cells. Cancer Res 62: 5230-5235, 2002.

7. Gupta AK, Cerniglia GJ, Mick R, McKenna WG and Muschel RJ: HIV protease inhibitors block Akt signaling and radiosensitize tumor cells both in vitro and in vivo. Cancer Res 65: 8256-8265 2005.

8. Jiang W, Mikochik PJ, Ra JH, Lei H, Flaherty KT, Winkler JD and Spitz FR: HIV protease inhibitor nelfinavir inhibits growth of human melanoma cells by induction of cell cycle arrest. Cancer Res 67: 1221-1227, 2007.

9. Plastaras JP, Vapiwala N, Ahmed MS, et al: Validation and toxicity of PI3K/Akt pathway inhibition by HIV protease inhibitors in humans. Cancer Biol Ther 7: 636-637, 2008.

10. Srirangam A, Mitra R, Wang M, et al: Effects of HIV protease inhibitor ritonavir on Akt-regulated cell proliferation in breast cancer. Clin Cancer Res 12: 1883-1896, 2006.

11. Piccinini M, Rinaudo MT, Anselmino A, et al: The HIV protease inhibitors nelfinavir and saquinavir, but not a variety of HIV reverse transcriptase inhibitors, adversely affect human proteasome function. Antivir Ther 10: 215-223, 2005

12. Timeus F, Crescenzio N, Ricotti E, Doria A, Bertin D, Saglio G and Tovo PA: The effects of saquinavir on imatinib-resistant chronic myelogenous leukemia cell lines. Haematologica 91: 711-712, 2006

13. Druker BJ and Lydon NB: Lessons learned from the development of an abl tyrosine kinase inhibitor for chronic myelogenous leukemia. J Clin Invest 105: 3-7, 2000.

14. Yalçin B, Kremer LC, Caron HN and van Dalen EC: High-dose chemotherapy and autologous haematopoietic stem cell rescue for children with high-risk neuroblastoma. Cochrane Database Syst Rev 12: CD006301, 2010.

15. Berthold F, Boos J, Burdach S, et al: Myeloablative megatherapy with autologous stem-cell rescue versus oral maintenance chemotherapy as consolidation treatment in patients with high-risk neuroblastoma: a randomized controlled trial. Lancet Oncol 6 : 649-658, 2005

16. De Bernardi B, Nicolas B, Boni L, et al: Disseminated neuroblastoma in children older than one year at diagnosis: comparable results with three consecutive high-dose protocols adopted by the Italian Co-Operative Group for Neuroblastoma. J Clin Oncol 21: 1592-1601, 2003

17. George RE, Li S, Medeiros-Nancarrow C, et al: High-risk neuroblastoma treated with tandem autologous peripheral-blood stem cell-supported transplantation: long-term survival up date. J Clin Oncol 24: 2891-2896, 2006.

18. Maris JM, Hogarty MD, Bagatell R and Cohn SL: Neuroblastoma. Lancet 369: 2106-2120, 2007.

19. Matthay KK, Villablanca JG, Seeger RC, et al: Treatment of high-risk neuroblastoma with intensive chemotherapy, radiotherapy, autologous bone marrow transplantation, and 13-cis-retinoic acid. Children's Cancer Group. N Engl J Med 341: 1165-1173, 1999.

20. Cohen PS, Chan JP, Lipkunskaya M, Biedler JL and Seeger RC: Expression of stem cell factor and c-kit in human neuroblastoma. The children's cancer group. Blood 84: 3465-3472, 1994.
21. Matsui T, Sano K, Tsukamoto T, et al: Human neuroblastoma cells express alpha and beta platelet-derived growth factor receptors coupling with neurotrophic and chemotactic signalling. J Clin Invest 92: 1153-1160, 1993.

22. Timeus F, Crescenzio N, Valle P, et al: Stem cell factor suppresses apoptosis in neuroblastoma cell lines. Exp Hematol 25: 1253-1260, 1997.

23. Uccini S, Mannarino O, McDowell HP, et al: Clinical and molecular evidence for c-kit receptor as a therapeutic target in neuroblastic tumors. Clin Cancer Res 11: 380-389, 2005.

24. Vitali R, Cesi V, Nicotra MR, et al: C-kit is preferentially expressed in MYCN-amplified neuroblastoma and its effect on cell proliferation is inhibited in vitro by STI-571. Int J Cancer 106: 147-152, 2003.

25. Beppu K, Jaboine J, Merchant MS, Mackall CL and Thiele CJ: Effect of imatinib mesylate on neuroblastoma. tumorigenesis and vascular endothelial growth factor expression. J Natl Cancer Ins 96: 46-55, 2004.

26. Te Kronnie G, Timeus F, Rinaldi A, et al: Imatinib mesylate (STI571) interference with growth of neuroectodermal tumour cell lines does not critically involve c-kit inhibition. Int J Mol Med 14: 373-382, 2004

27. Palmberg E, Johnsen JI, Paulsson J, et al: Metronomic scheduling of imatinib abrogates clonogenicity of neuroblastoma cells and enhances their susceptibility to selected chemotherapeutic drugs in vitro and in vivo. Int J Cancer 124: 1227-1234, 2009.

28. Bond M, Bernstein ML, Pappo A, Schultz KR, Krailo M, Blaney SM and Adamson PC: A phase II study of imatinib mesylate in children with refractory or relapsed solid tumors: a Children's Oncology Group study. Pediatr Blood Cancer 50: 254-258, 2008

29. Biedler JL, Helson L and Spengler BA: Morphology and growth, tumorigenecity, and cytogenetics of human neuroblastoma cells in continuous culture. Cancer Res 33: 2643-2652, 1973.

30. Biedler JL, Roffler-Tarlov S, Schachner M and Freedman LS: Multiple neurotransmitter synthesis by human neuroblastoma cell lines and clones. Cancer Res 38: 3751-3757, 1978.

31. Rocchi P, Ferreri AM, Simoni G and Prodi G: Epirubicin-induced differentation of human neuroblastoma cells in vitro. Anticancer Res 7: 247-250, 1987.

32. Sims JT and Plattner R: MTT assays cannot be utilized to study the effects of STI571/Gleevec on the viability of solid tumor cell lines. Cancer Chemother Pharmacol 64: 629-633, 2009.

33. Merry C, Barry MG, Mulcahy F, Halifax KL and Back DJ: Saquinavir pharmacokinetics alone and in combination with nelfinavir in HIV-infected patients. AIDS 11: 117-120, 1997.

34. Winston A, Mallon PW, Satchell C, et al: The safety, efficacy, and pharmacokinetic profile of a switch in antiretroviral therapy to saquinavir, ritonavir, and atazanavir alone for 48 weeks and a switch in the saquinavir formulation. Clin Infect Dis 44: 1475-1483, 2007.

35. Vitali R, Mancini C, Cesi V, et al: Slug (SNAI2) down-regulation by RNA interference facilitates apoptosis and inhibits invasive growth in neuroblastoma preclinical models. Clin Cancer Res 14: 4622-4630, 2008.

36. Kikuchi H, Sugiyama S and Imajoh-Ohmi S: A novel antiapoptosis serum factor that downregulates fas-mediated apoptosis. J Biochem 117: 936-939, 1995.

37. Tonelli R, Purgato S, Camerin C, Fronza R, Bologna F and Alboresi S: Anti-gene peptide nucleic acid specifically inhibits MYCN expression in human neuroblastoma cells leading to cell growth inhibition and apoptosis. Mol Cancer Ther 4: 779-786, 2005.

38. Fischer $\mathrm{M}$ and Brthold $\mathrm{F}$ : Characterization of the gene expression profile of neuroblastoma cell line IMR-5 using serial analysis of gene expression. Cancer Lett 190: 79-87, 2003.

39. Cohn SL, London WB, Huang D, et al: MYCN expression is not prognostic of adverse outcome in advanced-stage neuroblastoma with nonamplified MYCN. J Clin Oncol 18: 3604-3613, 2000. 